\title{
PREVALENCE OF CHILDHOOD OBESITY AND ITS SOCIO- PSYCHOLOGICAL EFFECTS ON PRIMARY SCHOOL CHILDREN IN THE CAPE COAST METROPOLIS, GHANA
}

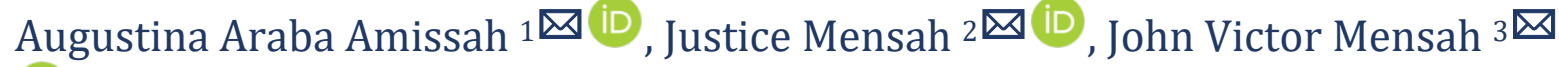 \\ (iD \\ ${ }^{1}$ Senior Lecturer, Department of Vocational and Technical Education, University of Cape Coast, \\ Ghana \\ ${ }^{2}$ Research Fellow, Directorate of Academic Planning and Quality Assurance, University of Cape \\ Coast, Ghana \\ ${ }^{3}$ Professor, School for Development Studies, University of Cape Coast, Ghana
}

DOI: https://doi.org/10.29121/granthaalayah.v9.i2.2021.3442

Article Type: Research Article

Article Citation: Augustina Araba Amissah, Justice Mensah, and John Victor Mensah. (2021).

PREVALENCE OF CHILDHOOD

OBESITY AND ITS SOCIO-

PSYCHOLOGICAL EFFECTS ON

PRIMARY SCHOOL CHILDREN IN

THE CAPE COAST METROPOLIS,

GHANA. International Journal of

Research -GRANTHAALAYAH, 9(2),

216-228.

https://doi.org/10.29121/granthaa

layah.v9.i2.2021.3442

Received Date: 04 February 2021

Accepted Date: 28 February 2021

Keywords:

Obesity

Prevalence of Obesity

Childhood Obesity

Socio-Psychological

Primary Schools

\section{ABSTRACT}

Childhood obesity is a major public health concern around the globe as it is associated with adverse consequences such as psychological problems, lower educational attainment, and a high risk of health challenges later in life. The study investigated the prevalence of obesity and its socio-psychological effects on primary school children in the Cape Coast Metropolis, Ghana. Interview schedule and interview guide were used to collect primary data from 317 pupils and 24 teachers respectively from public and private schools in 2018. Microsoft Excel software (version 2013) was used to analyse quantitative data while content analysis was used for qualitative data based on themes. The result indicated that the overall prevalence rate was five percent. Prevalence of obesity was higher in private schools than public schools while that among male pupils was higher than their female counterparts. Pupils of age 11 years were at higher risk than those at age nine years. The socio-psychological effects on the affected children included stigmatization, exclusion from taking part in some competitive activities, inactive and often slept during lessons. The school authorities should collaborate with the Metropolitan Directorates of Education and Health to manage obesity in the schools. They could invite health experts to educate school management, teachers, pupils, and parents on support systems for managing childhood obesity.

\section{INTRODUCTION}

Childhood is developmental period during which individuals establish basics for their future health through adolescence to adulthood (Morita et al., 2006). It is a complicated path that individuals take from dependency in childhood to independency in adulthood (Arnett, 2014). With the increasing prevalence in obesity, there is a corresponding number of youths classified as obese. Childhood obesity has become a global health issue due to its

(C) 2021 The Author(s). This is an open access article distributed under the terms of the Creative Commons Attribution License, which permits unrestricted use, distribution, and reproduction in any medium, provided the original author and source are credited. 
increasing prevalence and the consequences associated with it. Stigmatisation, low self-esteem and economic burden of managing childhood obesity make it imperative to pay particular attention to childhood obesity (Cunningham et al., 2014). An obese child in two consecutive years has a $\$ 194$ higher outpatient visit expenditure, a $\$ 114$ higher prescription drug expenditure, and a $\$ 12$ higher emergency room expenditure than a child with normal weight (Trasande \& Chatterjee, 2012).

Globally, 41 million children under age five and over 340 million children and adolescents aged 5-19 years were reported to be obese in 2016 (Akowuah, \& Kobia-Acquah, 2020). Obesity used to be considered a problem only in high-income countries but the phenomenon is on the rise in low- and middle-income countries (Pangani et al., 2016). Studies show that obesity cases are being recorded even at faster rate in low- and middle-income countries than the high-income countries (Dinsa et al., 2012). In Africa, the number of obese children almost doubled within the period of 16 years; increasing from 5.4 million in 1990 to 10.6 million in 2016 (Ganle et al., 2019).

Childhood obesity is emerging as a major health problem in Ghana, especially among the urban population. Ghana Statistical Service (2014a) indicated that childhood obesity has grown at an alarming rate of 3.1 percent in Ghana with Greater Accra, Central and Volta regions reporting high levels of the incidence. Whyte et al. (2020) noted that about five percent of school children in Cape Coast were obese and nine percent were at risk of obesity. This is particularly important because childhood obesity can negatively affect academic work of school children. Studies have shown that overweight children tend to become overweight or obese adults (Biro \& Wien, 2010). Effective prevention and management of obesity during childhood are critical to prevent the situation from becoming epidemic in the society. Prevention and effective management of childhood obesity demand the need to undertake an evidenced-based study to estimate its prevalence among children in Ghanaian schools and disaggregate such information by sex and age (Atuahene et al., 2017). One key step in managing childhood obesity and its attendant challenges is to undertake comprehensive studies of its prevalence and causes. There is limited data on prevalence of childhood obesity disaggregated by age and sex in Ghana (Ganle et al., 2019). It is against this background that this study is undertaken.

The study investigates the prevalence of childhood obesity and its socio-psychological effects on primary school children in the Cape Coast Metropolis in Ghana. The specific objectives of the study are to: (a) determine the prevalence of childhood obesity among the primary school children; and (b) analyse the effects of childhood obesity on socio-psychological aspects of school children.

The paper is structured into five sections, beginning with introduction which captures the background to the paper. The next section is literature review. The third section presents the methods used for the study while the fourth section focuses on results and discussion. The final section presents conclusion and the way forward.

\section{LITERATURE REVIEW}

Literature is reviewed on obesity as a concept, childhood obesity, prevalence of childhood obesity, causes of childhood obesity, and socio-psychological consequences of childhood obesity.

\subsection{OBESITY AS A CONCEPT}

Obesity refers to a physical condition characterized by excessive deposition or storage of fats in the adipose tissues (Barkhru, 2006). It is an abnormal fat accumulation resulting from energy imbalance between calories consumed and calories expended. A person is considered obese when his/her body mass index (BMI) exceeds $30 \mathrm{~kg} / \mathrm{m}^{2}$, with the range of $25-30 \mathrm{~kg} / \mathrm{m}^{2}$ defined as overweight (Haslam \& James, 2005). The Centre for Disease Control and Prevention (2010) defines overweight as at or above the $95^{\text {th }}$ percentile of BMI for age and "at risk for overweight" as between 85 th and 95th percentile of BMI for age (Himes \& Dietz 1994; Flegal et al., 2002). Obesity impedes the health of the individual and can cause diseases and death that could be prevented. Therefore, it is important to curb its prevalence.

\subsection{CHILDHOOD OBESITY}

Childhood is the period of the human lifespan between infancy and adolescence, extending from ages 1-13 (Encyclopaedia Britannica). It is a period during which individuals acquire foundation skills for their future health, 
growth and development. Childhood obesity occurs when a child is well above the normal weight for his/her age and height (Truswell, 2003). Many paediatricians classify a child as obese when the child falls above the $95^{\text {th }}$ percentile in weight for height. A child whose BMI for age percentile is greater than $95^{\text {th }}$ percentile, is classified as obese. However, a child's BMI-for-age percentile between $85 \%$ and 95\%, is classified as overweight (WHO, 2007).

Body Mass Index is a simple calculation using a person's height and weight. The formula is BMI $=\mathrm{kg} / \mathrm{m}^{2}$ where $\mathrm{kg}$ is a person's weight in kilograms and $\mathrm{m}^{2}$ is their height in square metres. A BMI of 25.0 or more is overweight, while the healthy range is 18.5 to 24.9 . BMI applies to most adults 18-65 years. Obesity is diagnosed when the BMI is 30 or higher.

Table 1: Body mass index and weight status

Source: Diabetes Canada (2020)

\begin{tabular}{|c|c|}
\hline Body Mass Index & Weight Status \\
\hline Below 18.5 & Underweight \\
\hline $18.5-24.9$ & Normal \\
\hline $25.0-29.9$ & Overweight \\
\hline 30.0 and higher & Obesity \\
\hline
\end{tabular}

\subsection{PREVALENCE OF OBESITY AMONG SCHOOL CHILDREN}

The prevalence of overweight and obesity among males and females differs within and between countries but generally, females are more obese than males in developing countries. Yet, in developed countries, more males are overweight than females (Kanter \& Caballero, 2012)

Literature suggests that several sociocultural dynamics throughout the world intensify gender disparities in excess weight gain. The causes of overweight and obesity among girls and boys may be different due to biological make-up, society and culture (Kumanyika et al., 2002). Boys and girls differ in body composition, patterns of weight gain, hormone biology, and the susceptibility to certain social, ethnic, genetic, and environmental factors (Popkin, 2011). Understanding gender differences in child overweight and obesity risk and associated determinants is critical for the policy formulation and execution.

Gender variations in prevalence of childhood obesity have been noted in several countries. Some studies reported higher prevalence in girls than in boys (Gortmaker, 2011) while others have reported the contrary (McLaren, 2007). Muhihi et al. (2013) observed that the overall incidence of childhood obesity among primary school children in Dar es Salaam was 5.2\%. Obesity was highlighted as higher among girls (6.3\%) than boys (3.8\%). Similarly, the prevalence of overweight was higher among girls $(13.1 \%)$ than boys $(6.3 \%)$.

Pangani et al. (2016) noted that prevalence of underweight, overweight and obesity among primary school children aged 8-13 years in Dar es Salaam City were 5.5\%, 18.7\%, and 8.0\% of females and 7\%, 12.1\%, and 4.9\% of males respectively. The result showed that more males were found to be underweight (7\%) than females (5.5\%) while more females were found to be overweight or obese (26.7\%) than males (17\%). Mohammed and Vuvor (2012) observed that childhood obesity or overweight ranked very high among the females in basic schools in Accra. They observed $10.9 \%$ prevalence of child obesity with higher prevalence in girls (15.0\%) than boys (7.2\%). The difference was statistically significant $(\mathrm{P}$-value $=0.001)$.

The Ghana Statistical Service (2014a) revealed that obesity among children was growing at the rate of 3.1\%. Amidu et al. (2013) reported that the overall prevalence of overweight and obesity among the sampled children in Tamale drawn from the private and public schools was $9.8 \%$ and $7.5 \%$ respectively. This suggests that the children from the private schools were heavier than their counterparts from the public schools. Tuoyire et al. (2018) however, observed that obesity is prevalent in Cape Coast and appears to cut across all adult age groups.

\subsection{CAUSES OF CHILDHOOD OBESITY}

Genetics is one of the causes of obesity. Some studies have found that BMI is $25-40 \%$ heritable (Anderson \& Butcher, 2006). Many obese children grow to become obese adults, especially if one or both parents are obese. However, hereditary predisposition often needs to be coupled with contributing environmental and behavioural 
factors in order to affect weight (Institute of Medicine (US), 2004). While genetics can play a role in the development of obesity, it is not always the cause of the dramatic increase in childhood obesity. Metabolism has also been identified as a potential cause of obesity. It is the body's expenditure of energy for normal resting functions. Diet has been studied extensively for its possible contribution to the increasing rates of obesity among children. Several dietary factors examined include fast food consumption, sugary beverages and snack foods. Increased fast food consumption has been linked to obesity in the recent years (Niehoff, 2009). Fast food often contains high calories with low nutritional values. Sugary drinks include soda, juice and other sweetened beverages, which result in a higher caloric intake (Chen et al., 2012).

Sedentary lifestyles coupled with lack of or inadequate physical exercise also cause obesity (Anderson \& Butcher, 2006). The increased amount of time devoted to inactive behaviours tends to decrease the amount of time spent in physical activity. The number of hours children spend watching television correlates with their consumption of the most advertised goods such as sweets, sweetened cereals, sweetened beverages and snacks (Story et al., 2002). The use of electronic media and other environmental factors reduce the opportunities for physical activity (Krushnapriya et. al., 2015). For example, in the past, most children either walked or rode their bicycles to school but today, most affluent parents drive their children to school, even in developing countries. Anderson and Butcher (2006) noted that $53 \%$ of the parents drove their children to school, thereby making their wards to be physically inactive and exposing them to the risk of obesity and overweight.

Psychological factors such as depression and anxiety can also cause obesity (Goldfield et al., 2010). In a clinical study of obese adolescents, a higher life-time prevalence of anxiety disorders was reported compared to non-obese controls (Britz et al., 2000). In contrast, Tanofsky-Kraff et al. (2004) reiterated that some studies demonstrate no significant relationship between increased BMI and increased anxiety symptoms.

\subsection{SOCIO-PSYCHOLOGICAL CONSEQUENCES OF CHILDHOOD OBESITY}

Childhood obesity is an austere medical condition that affects children because the extra kilograms often start children on the path to poor health conditions that were hitherto considered adult problems such as diabetes, high blood pressure and high cholesterol (Cote et al., 2013). It can also lead to poor self-esteem and depression.

Childhood obesity has several consequences as it can affect children's physical health, social, and psychological well-being including emotions and self-esteem, and academic performance (Krushnapriya et al., 2015). It has been connected to various health conditions such as fatty liver disease, sleep apnea, Type 2 diabetes, asthma, hepatic steatosis, cardiovascular disease, high cholesterol, gallstones, glucose intolerance and insulin resistance, skin conditions, menstrual abnormalities, impaired balance, and orthopaedic problems (Niehoff, 2009). Until recently, many of the above health conditions had only been found in adults; now they are extremely prevalent in obese children. Most of the physical health conditions related to childhood obesity are preventable and can disappear when a child attains a healthy weight while some continue to have negative effects during adulthood (American Academy of Pediatrics, 2019). Some of these poor health conditions may lead to death.

Childhood obesity also affects children's social and emotional health. It is one of the most stigmatizing and least socially acceptable conditions (Schwimmer et al., 2003). Overweight and obese children are often teased and/or bullied. They also suffer miseries such as negative labels, discrimination and social marginalization (Budd \& Hayman, 2008). Obese children are frequently excluded from competitive activities that require smartness. The abovementioned negative effects can be devastating to children and adolescents, especially when they are in school.

The negative social effects of obesity may contribute to long-term difficulty in weight management. Obese children often safeguard themselves from stigmatization by withdrawing from interacting with friends and other people (Cornette, 2008). Childhood obesity has negative effect on academic performance. According to Schwimmer et al. (2003), overweight and obese children are four times more likely to report having problems at school than their normal weight peers. In addition, they are more probable to miss school often particularly, those with chronic diseases such as diabetes and asthma.

\section{STUDY AREA AND METHODS}

The study was conducted in the Cape Coast Metropolis which is the capital of the Central Region of Ghana (Figure 1). The Metropolis shares boundary to the South by the Gulf of Guinea, to the West by Komenda-Edina- 
Eguafo-Abrem Municipality, to the East by the Abura-Asebu-Kwamankese District and to the North by the Twifo Heman Lower Denkyira District. Its location is on the longitude of $1^{\circ} 14^{\prime}-1^{\circ} 15^{\prime} \mathrm{W}$ and latitude $5^{\circ} 05^{\prime}-6^{\circ} .00^{\prime} \mathrm{N}$ and occupies an area of approximately 122 square kilometres. The population of the Cape Coast Metropolis was 169,894 in 2010 , representing $7.7 \%$ of the total population of the Central Region. The population constituted 48.7 percent males and 51.3 percent females, among which the proportion of children below 15 years was 28.4 percent. The economic activity status of the entire population is very high with about $54.7 \%$ of children age 15 and above being economically active. There were about 21,178 primary school pupils in the Metropolis in 2010 (Ghana Statistical Service, 2014b). The Metropolis was chosen for the study because it is considered as the citadel of education in Ghana. It has many schools ranging from basic to tertiary level. Records obtained from the Cape Coast Metropolitan Education Office in 2018 showed 120 primary schools (80 public and 40 private).

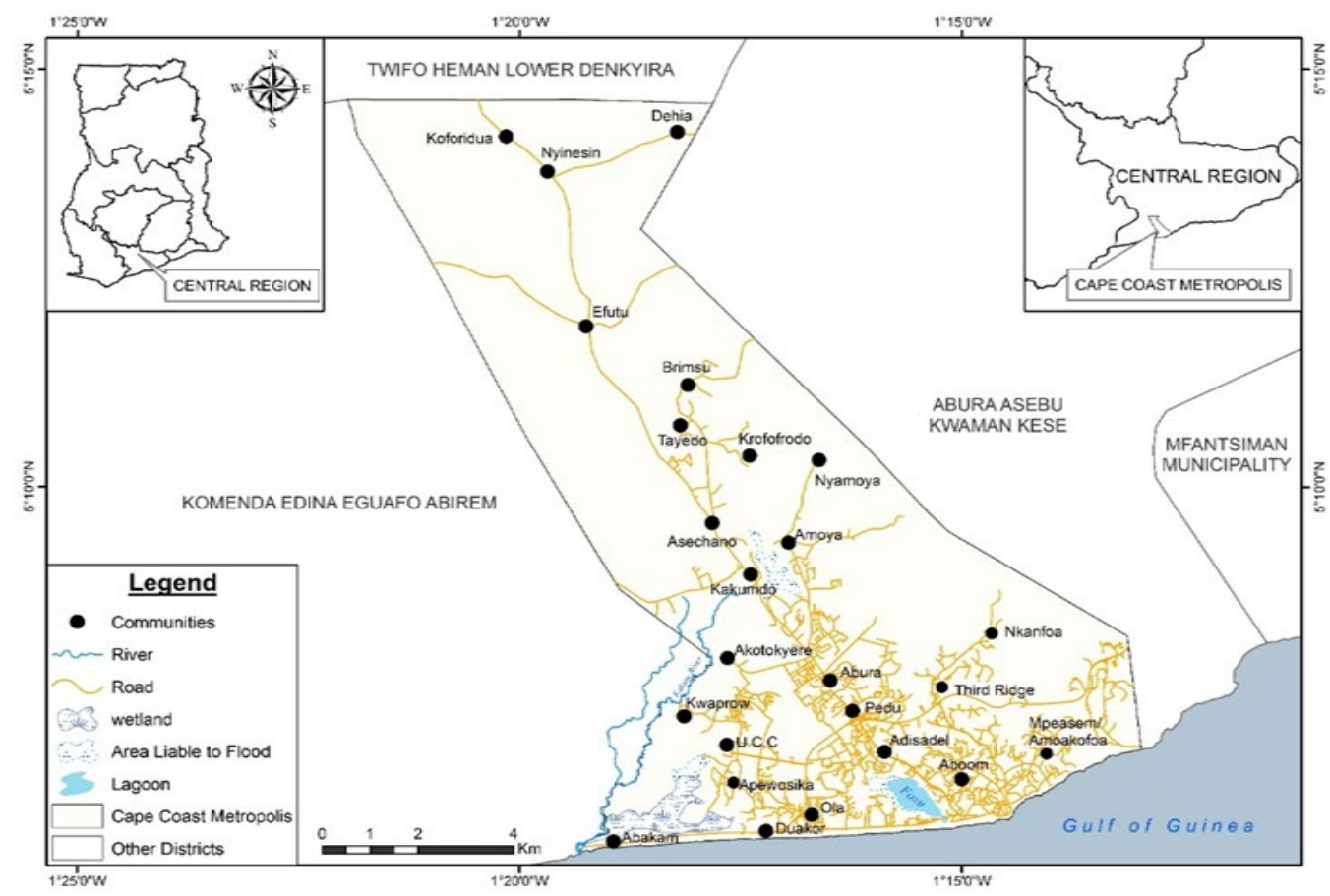

Figure 1: Map of Cape Coast Metropolis

Source: Cartography Unit, Department of Geography and Regional Planning, UCC (2018).

The study adopted the mixed method approach. Both quantitative and qualitative data were used. The target population was all school-aged pupils between the age range of 9 and 15 years. For this study, pupils from primary four to six were selected from 12 schools in the Metropolis. This is because it was assumed that they were old enough and more likely to understand the requirements for the study. The inclusive criteria for the study were all primary four to six pupils who were available, willing and had their parents/guardians' consent for their participation. It excluded pupils whose parents or guardians did not give their consent for their participation and those with physical deformities that could affect the accuracy of the anthropometric measurements.

For representativeness, reliability and flexibility in the study, a justified sample size was obtained. Cohen, Manion and Morrison (2007) are of the opinion that sample size can be obtained in two ways; the researcher can either carefully ensure that the sample is a good representation of the wider population or by using a table which forms a mathematical formula. Based on this, the Krejcie and Morgan (1970) table for determining sample size was used. As laid down by them, for a population between 20,000 and 30,000, a sample size of about 379 is appropriate for a study. However, a sample size of 317 was obtained and used because of availability and approval of parents or guardian to participate in the study. These comprised $169(53 \%)$ females and $148(47 \%)$ males. Both males and females were selected because of the differences in their physiological and genetic make-up. These differences were perceived to possibly affect their tendency of acquiring or accumulating excess body fat. In addition, 136 out of these 317 pupils, representing $42.9 \%$, were selected from private schools and 181 also representing $57.1 \%$ were selected 
from public schools. This was also done to make it possible to compare the prevalence of obesity among the pupils from both clusters.

The multi-stage sampling procedure was adopted to select participants for the study. The procedure involved four steps. First, the total number of all primary schools was obtained from the six circuits in the Cape Coast Metropolitan Education Directorate. Second, a sampling frame was made using the list of schools based on their categories: private and public. Two schools (one private and one public) from each circuit were then selected from the six circuits in the Metropolis using the simple random (lottery) method. Third, the lottery method with replacement was used to select the sample of 32 pupils from each selected school. This was done by compiling the list of all primary four to six pupils using their class registers. During data collection, a sample size of 317 pupils were available and approved by their parents for use for the study. Fourth, two teachers from each of the 12 selected schools (i.e., 24 teachers) were involved in the in-depth interview to provide information on the effects of childhood obesity on socio-psychological aspects of the school children.

For the purpose of this study, anthropometric measurements were used for data collection. A standardised UNICEF electronic scale produced by SECA (a German company that develops, produces and sells weighing scales and measuring instruments) and a height rod were used to take weight and height measurements of the school pupils respectively following standard procedures outlined by Gibson (2005). Heights were recorded to the nearest 0.1 centimetre while weights were recorded to the nearest 0.1 kilogram.

An in-depth interview guide was developed to collect qualitative data from teachers in the selected schools. Two research assistants were recruited and trained to assist in the data collection. During the training, they were briefed on appropriate data collection (weight and height measurements procedures) and ethics. A pre-test of the instruments for data collection was carried out in three primary schools using five pupils from each school who did not form part of the sample for the main study. This was to test the procedures outlined above and to check the reliability of the weighing scale and the height rod used.

A letter of introduction was sent to school authorities to seek permission from the Ghana Education Service as well as various heads of schools selected. After the school authorities agreed for the study to be undertaken, consent letters were sent to parents/guardians of all selected pupils in classes four to six through their children. Children whose parents granted consent were included in the study. Data collection took place from $17^{\text {th }}$ September to $25^{\text {th }}$ October, 2019. The pupils were refreshed with biscuits and yoghurt by way of compensation for participation.

Social scientists observe ethical considerations and cannot carry out research that involves people without an informed consent (Israel \& Hay, 2006). An introductory letter was sent to the authorities of the Cape Coast Metropolitan Assembly to seek clearance to conduct the study as well as to the Educational Unit. Ethical approval was sought from the University of Cape Coast Institutional Review Board (UCCIRB) before conducting the studies. The researchers adhered to all the ethical issues that supported research work. All respondents were given much information needed to make an informed decision about whether or not they wished to participate in the study. Moreover, respondents were assured that, information provided would be treated as confidential as possible. Also, as part of exercising a high level of confidentiality, anonymity was highly addressed to ensure that the research was devoid of the names of the participants.

The anthropometrical measures were taken in the mornings on the school premises. The research team ensured that though participants were in their usual school uniform, they were without foot wear, socks, watches, and items in their pockets or any heavy clothing like jacket or sweater. Body weight was measured using a weighing scale. The scale was placed on a flat surface and stepped on for it to display $0.0 \mathrm{~kg}$. Participants' data such as age, height and sex were recorded. Each participant stepped onto the scale with one foot on each side of the scale. They were also asked to stand still, face forward, place arms on the side and wait until asked to step off. Weight and BMI figures that appeared on the screen were recorded.

Height was measured using a height rod fixed appropriately to a wall. They were then asked to stand with their backs straight, and arms hanging loose by their sides with feet flat, buttock, shoulder blades and head touching the wall. The height rod was aligned to the vertex of the head and readings recorded.

The data were coded, entered into computer and analysed using the Microsoft Excel software (version 2013) to generate tables and graphs using frequency and percentage distributions. Microsoft Excel was used to calculate the BMIs using the heights and weights of the pupils to confirm the readings from the weighing scale. BMI was calculated as weight $(\mathrm{kg}) /$ height $\left(\mathrm{m}^{2}\right)$. The World Health Organization's (2007) BMI-for-age chart was used to classify the BMI status of the pupils. Thereafter, descriptive statistics were used to calculate and determine the prevalence of obesity among the pupils and chi-square values were calculated to establish whether or not there were significant 
differences in BMI in terms of sex, age and type of school children attended. The qualitative data were transcribed and content analysis was applied. Responses to items in the interview guide were analysed through the categorization of emergent and common themes.

\section{RESULTS AND DISCUSSION}

This section presents the analysis and discussion of data on prevalence of obesity among primary school children based on sex, age and the type of school children attended as well as the effects of childhood obesity on socio-psychological aspects of school children.

\subsection{PREVALENCE OF CHILDHOOD OBESITY}

The overall prevalence of obesity among the sampled primary pupils was 4.7 percent of the total number of pupils as presented in Figure 2. Fifteen (4.7\%) pupils were obese. Pupils at risk of obesity (overweight) were 29 $(9.2 \%)$ representing almost twice the number of obese pupils. The implication is that the combined prevalence of obesity and overweight was 13.9 percent.

The results are in line with other studies on the prevalence of obesity among children. Child obesity is growing in the Central Region at the rate of 4.6 percent (Ghana Statistical Service, 2014a). Amidu et al. (2013) revealed that the combined obesity and those at risk of obesity among basic school pupils in the Tamale metropolis was 17.6 percent. Aduama (2004) noted that the prevalence of obesity and overweight among primary school pupils in the Greater Accra Region was 5\% and 10.2\% respectively, thereby giving a combined prevalence of obesity and risk of obesity as 15.2 percent. Nicklas et al. (2001) indicated that 25 percent and 11 percent of children in the USA were overweight and obese respectively and about 70 percent of the obese children grow up to become obese adults.

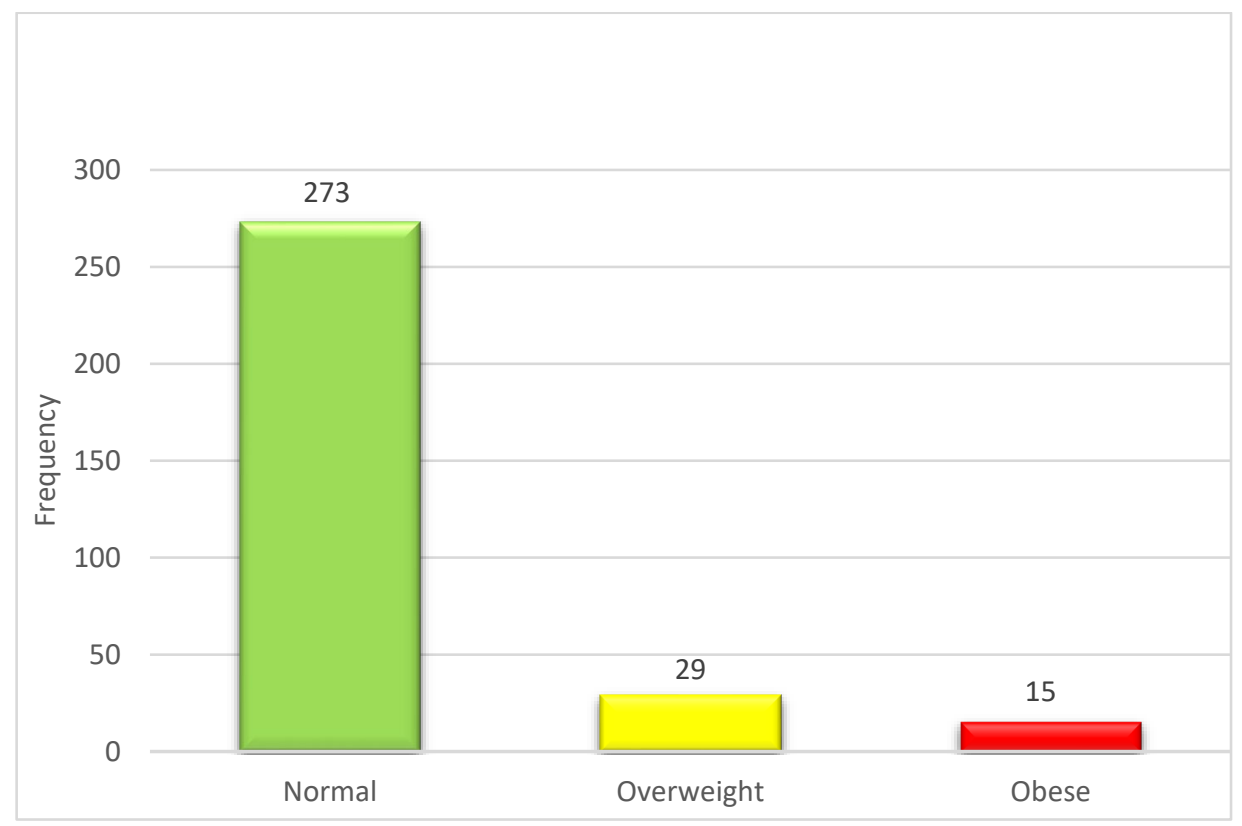

Figure 2: Overall prevalence of obesity

Source: Field data, 2019

\subsection{PREVALENCE OF OBESITY BY SEX}

The sample for the study comprised 169 (53.3\%) females and 148 males (46.7\%). The result indicates obesity prevalence rates of $6.1 \%$ and $3.6 \%$ among the males and females respectively as presented in Table 2 . This shows that the prevalence rate of obesity among the males was almost twice as that of females. 
Table 2: Prevalence of obesity by sex

\begin{tabular}{|c|c|c|c|c|}
\hline Sex & Normal & Overweight & Obese & Total \\
\hline Male & $123(83.1)$ & $16(10.8)$ & $9(6.1)$ & $148(100.0)$ \\
Female & $150(88.8)$ & $13(7.7)$ & $6(3.6)$ & $169(100.0)$ \\
\hline Total & $273(86.1)$ & $29(9.1)$ & $15(4.7)$ & $317(100.0)$ \\
\hline \multicolumn{2}{|c|}{ Chi-square statistic $=2.199$} & \multicolumn{4}{|c|}{ P-value $=0.33$} \\
\hline
\end{tabular}

Note: Figures in parentheses are row percentages; Significance level $=0.05$

Source: Field data, 2019

Table 2 indicates that there was no statistical difference between the obese pupils from both sexes and the overweight pupils, although those at risk of obesity or overweight was at an alarming rate of $10.8 \%$ males and $7.7 \%$ females. However, the difference in weight by sex was statistically insignificant as indicated by chi-square value of 2.199 with p-value $=0.33$, which is higher than 0.05. Our finding is consistent with that of $\mathrm{Ng}$ et al. (2014) that there were more obese males than females in developed countries. However, it is inconsistent with that of Mohammed and Vuvor (2012) who observed a higher prevalence of obesity of 15\% among females than $7.2 \%$ among males in Accra. Mohammed and Vuvor (2012) concluded that the higher prevalence rate among females may be due to hormonal changes and other factors.

\subsection{PREVALENCE OF OBESITY BY AGE}

The age of the sampled pupils ranged from 9 to 15 years. The prevalence of obesity by age of the pupils is presented in Figure 3. The prevalence of obesity was high among pupils of age $11(2.2 \%)$ for both sex classifications and was also very low at age nine $(0.32 \%)$. However, there were more pupils at the age of $10(3.2 \%)$ who were overweight and at risk of being obese. This implies that obesity and risk of obesity were highly seen among pupils within the age range of 10-12 years. The result suggests that the difference in weight of children by age was statistically insignificant as shown by chi-square value of 8.214 (p-value $=0.41$ ).

The results corroborate Muhihi et al.'s (2013) finding that, children aged 10 years and above were three times more likely to develop obesity. This is also confirmed by the American Heart Association (2009) that when children entered kindergarten (mean age 5.6 years), $12.4 \%$ were obese and $14.9 \%$ overweight but as they entered eighth grade (mean age 14.1years), 20.8\% were obese and 17.0\% were overweight. McLaren et al. (2003) studied the relationship between past body size and current body dissatisfaction among 933 middle-aged women and found out that, women who were dissatisfied at mid-life were found to have been overweight at age seven and showed a more rapid increase in BMI with age. Obese children are more likely to become obese adolescents or adults (Barkhru, 2006).

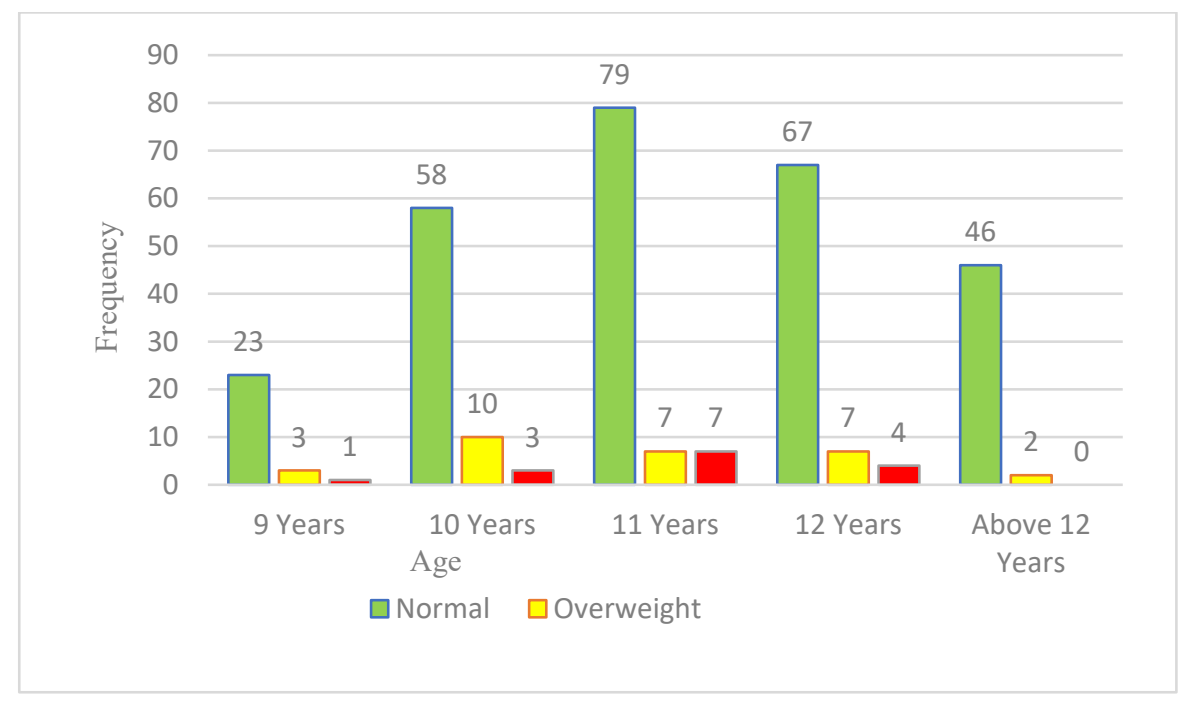

Source: Field data, 2019

Figure 3: Prevalence based on age 
Prevalence of Childhood Obesity and Its Socio-Psychological Effects on Primary School Children in the Cape Coast Metropolis, Ghana

\subsection{PREVALENCE BASED ON TYPE OF SCHOOL CHILDREN ATTENDED}

The prevalence of childhood obesity based on type of school children attended is illustrated in Table 3 . There were more obese pupils in the private schools $9(2.8 \%)$ than those found in the public schools $6(1.9 \%)$. In terms of those overweight and at risk of obesity, the results showed higher prevalence among private schools 16 (5\%) than those found in the public schools, 13 (4.1\%). This finding is in line with the assertion of Amidu et al. (2013) that the mean percentage of body fat among the pupils in the private schools was significantly higher than those from the public schools. This may be due to differences in the socio-economic backgrounds of parents of private schools and those of public schools. Literature suggests that variations in factors such as lifestyle, dietary behaviours and standard of living occasioned by socio economic status could explain an individual's social environment, physical environment and macro-level environments all of which interact to impact energy intake and physical activity behaviours (American Heart Association, 2009). Chi-square analysis emerging from our study shows that the difference in weight of children by type of school children attended was statistically insignificant as indicated by chisquare value of 4.133 with $\mathrm{p}$-value $=0.13$.

Table 3: Prevalence based on type of school children attended

\begin{tabular}{|c|c|c|c|}
\hline Condition & Public & Private & Total \\
\hline Normal & $162(51.1)$ & $111(35.0)$ & $273(86.1)$ \\
Overweight & $13(4.1)$ & $16(5.0)$ & $29(9.2)$ \\
Obese & $6(1.9)$ & $9(2.8)$ & $15(4.7)$ \\
\hline Total & $181(57.1)$ & $136(42.9)$ & $317(100.0)$ \\
\hline \multicolumn{2}{|c|}{ Chi-square statistic $=4.133$} & \multicolumn{2}{|c|}{ P-value $=0.13$} \\
\hline
\end{tabular}

Note: Figures in parentheses are row percentages; Significance level $=0.05$

Source: Field data, 2019

\subsection{EFFECTS OF CHILDHOOD OBESITY ON SOCIO-PSYCHOLOGICAL ASPECTS OF SCHOOL CHILDREN}

Interactions with the teachers and the children revealed that overweight and obese children face sociopsychological problems which included stigmatization, teasing, bullying, marginalisation, negative stereotyping, discrimination, absenteeism, poor academic performance, poor health conditions and unhappiness. For example, a 43-year-old female teacher reported that:

Some children tease their obese friends but the teachers have warned them against that. I even punished some pupils for teasing their obese friends (Private school teacher, 19th September, 2019).

This statement confirms the assertion of Schwimmer et al. (2003) that obese and overweight children are often teased, bullied and stigmatized.

Another teacher reported that some obese children were marginalized as they were often excluded from taking part in some competitive activities such as soccer and athletics. One of the teachers remarked that:

Some of the obese children are not happy about not being selected to take part in sporting activities (Public school teacher, 25 $5^{\text {th }}$ September, 2019).

This corroborates the findings of Schwimmer et al. (2003), American Academy of Paediatrics (2019) and Budd and Hayman (2008) that obese and overweight children suffer negative stereotypes, discrimination and marginalization.

The teachers also reported that some obese children often sleep in class and the children concerned do not benefit from the lessons being taught. For example, a teacher highlighted that:

I have two obese children in my class. They are not active at all. They are always sleeping during lessons. Although some other children sometimes sleep in the class, I suspect that for these two obese children it is due to their condition. They are also not academically good (Public school teacher, 9th October, 2019).

In one of the schools, it was indicated that there was an obese child who frequently absented herself from school due to ill health. The class teacher lamented that:

The child's performance was not good but she could have done better as she was not dull but she has been missing classes (Private school teacher, 14th October, 2019). 
This result corroborates the finding of Krushnapriya et al. (2015) that overweight and obese children are likely to miss school more frequently, especially those with health conditions such as diabetes and asthma.

One female obese child reported that:

My friends have given me a nickname 'Obolo' which means I am too big or fat. I have told them I do not like it but they still call me by the nickname (A female private school child, 14th October, 2019).

The child's report was corroborated by two teachers in the school and three in other schools that:

School children have nicknames for their obese counterparts. Most obese school children do not like such names. But some school children are stubborn as they continue to harass them in one way or the other with the nicknames. However, the teachers do not spare the offenders when reports reach them. It is important to note that some obese children do not mind their friends calling them by the nicknames (Private school teacher, 14th October, 2019).

In another school, a male obese child reported that:

When the friends are playing soccer and he wants to join them, they do not allow him because they say he is too big and heavy as he might hurt someone. (Public school child, 26 $6^{\text {th }}$ September, 2019).

Three teachers confirmed the boy's report indicating that they had punished two boys on this issue after advising them a couple of times to no avail to refrain from that behaviour. Besides, all the teachers confirmed that obese children usually had one challenge or the other due to their condition but they (the teachers) were doing their best to contain the situation.

The foregoing reports are consistent with the findings of Budd and Hayman (2008) and Krushnapriya et al. (2015) that some obese children face hardships including negative stereotypes, discrimination and social marginalization. These negative effects can be devastating to children and adolescents, especially when they are in school.

\section{CONCLUSION AND THE WAY FORWARD}

The paper has provided evidence that the prevalence rate of obesity among primary school children in the Cape Coast Metropolis was 4.7 percent. The prevalence of obesity was almost twice among males than females. Overweight was also higher among males (10.6\%) than females (7.7\%). In terms of age, pupils within 10-12 years were found to be most highly at risk of obesity. For both sex, pupils of age 11 were highly at risk (2.2\%) while those at age nine were found to be at low risk.

Prevalence of obesity was higher among primary school children in private schools than their public-school counterparts. Overweight was also higher in private schools than the public ones. The socio-psychological effects on obese children in the schools include stigmatization, marginalization and exclusion from taking part in some competitive activities. Additionally, some obese children were not active and often slept during lessons, thereby making them not good academically. The findings of this study suggest that obesity and overweight among school children in the Cape Coast Metropolis were high. These could pose challenges to both pupils and teachers in academic work. However, chi-square results show that there was no statistically significant difference in weight of school children by sex, age and type of school children attended.

As a way forward, the schools should collaborate with the Metropolitan Directorate of Education and parents to find ways of reducing the incidence of obesity among pupils in the schools. They should collaborate with health experts to educate the teachers, parents and pupils on both reducing and managing obesity among pupils. Since this case study used a relatively small sample, there is need for a nation-wide study on obesity and overweight among school children to guide national policy and obesity management.

\section{SOURCES OF FUNDING}

This research received no specific grant from any funding agency in the public, commercial, or not-for-profit sectors.

\section{CONFLICT OF INTEREST}

The authors have declared that no competing interests exists. 
Prevalence of Childhood Obesity and Its Socio-Psychological Effects on Primary School Children in the Cape Coast Metropolis, Ghana

\section{ACKNOWLEDGMENT}

None.

\section{REFERENCES}

[1] Aduama, S. (2004). Obesity in primary school children in Accra Metropolis. Dissertation submitted to the School of Public Health, University of Ghana, Legon, for the award of Master of Public Health http://ugspace.ug.edu.gh/bitstream/handle/123456789/5103/

Svitlana\%20Aduama_Obesity\%20in\%20primary\%20school\%20children\%20in\%20Accra\%20Metropolis_2 004.pdf?sequence=3\&isAllowed=y

[2] Akowuah, P. K., \& Kobia-Acquah, E. (2020). Childhood Obesity and Overweight in Ghana: A Systematic Review and Meta-Analysis. Journal of Nutrition and Metabolism, Article ID 1907416, 11 pp., 2020. https://doi.org/10.1155/2020/1907416.

[3] American Academy of Pediatrics (2019). About childhood obesity. Itasca: American Academy of Pediatrics, Available from: http://www.aap.org/obesity/about.html.

[4] American Heart Association (2009). Understanding childhood obesity, Texas: National Center.

[5] Amidu, N., Owiredu, W., Saaka, M., Quaye, L., Wanwan, M., Kumibea, P., Zingina, F., \& Mogre, V. (2013). Determinants of childhood obesity among basic school children aged 6-12 years in Tamale Metropolis. J Med Biomed Sci. 2(3):26-34.

[6] Anderson P. M., \& Butcher, K. E. (2006). Childhood obesity: trends and potential causes. Future Child, 16(1), 19-45. doi: $10.1353 /$ foc.2006.0001.

[7] Arnett, J. J. (2014). Emerging adulthood: The winding road from the late teens through the twenties. New York: Oxford University Press.

[8] Atuahene M., Ganle, J. K., Adjuik, M., Atuahene, N. F., \& Kampitib, B. G. (2017). Overweight and obesity prevalence among public servants in Nadowli district, Ghana, and associated risk factors: a cross-sectional study. BMC Obesity. https://doi.org/10.1186/s40608-017-0153-5.

[9] Barkhru, H. K. (2006). Nature cure for children's diseases. http://www. HealthLibrary.com.

[10] Biro, F. M., \& Wien, M. (2010). Childhood obesity and adult morbidities, The American Journal of Clinical Nutrition. 91(5), 1499S-1505S.

[11] Britz, B., Siegfried, W., Ziegler, A., Lamertz, C, Herpertz-Dahlmann, B.M., Remschmidt, H., et al. (2000). Rates of psychiatric disorders in a clinical study group of adolescents with extreme obesity and in obese adolescents ascertained via a population-based study. Int J Obes Relat Metab Disord, 24:1707-14.

[12] Budd, G.M., \& Hayman, L.L. (2008). Addressing the childhood obesity crisis. Am J Matern Child Nurs. 33:1137.

[13] Center for Disease Control and Prevention. (2010). Contributing factors. Available from: http://www.cdc.gov//obesity/childhood/contributing_factors.html

[14] Chen, S. E., Raymond J., Florax, R. J., \& Snyder, S. D. (2012) Obesity and fast food in urban markets: A new approach using geo-referenced micro data. Health Economics, 22(7), 835856.https://doi.org/10.1002/hec.2863

[15] Cohen L, Manion, L. \& Morrison, K. (2007). Research Methods in Education, (6th ed.), London: Routridge

[16] Cornette, R. (2008). The emotional impact of obesity on children. Worldviews Evid Based Nurs. 5,136-41.

[17] Cote, A.T., Harris, K. C., Panagiotopoulos, C., et al. (2013). Childhood obesity and cardiovascular dysfunction.J Am Coll Cardiol; 62 (15):1309-1319.

[18] Cunningham, S. A., Kramer, M. R., \& Narayan, K. M. V. (2014). Incidence of childhood obesity in the United States. $N$ Endl J Med, 11 370-403.

[19] Desalew, A., Mandesh, A., \& Semahegn, A. (2017), Childhood overweight, obesity and associated factors among primary school children in dire dawa, Eastern Ethiopia; A cross-sectional study. BMC Obes. doi: 10.1186/s40608-017-0156-2.

[20] Diabetes Canada (2020). Body Max Index (BMI) Calculator, Toronto: National office.

[21] Dinsa, G. D., Goryakin, Y., Fumagalli, E., \& Suhrcke, M. (2012). Obesity and socioeconomic status in developing countries: A systematic review. Obesity reviews, 13(11), 1067-1079. 
Augustina Araba Amissah, Justice Mensah, and John Victor Mensah

[22] Flegal, K.M., Wei, R., \& Ogden, C. (2002). Weight-for-stature compared with body mass index-for-age growth charts for the United States from the Centers for Disease Control and prevention. Am J Clin Nutr, 75,761-766.

[23] Ganle, J. K., Boakye, P. P., \& Baatiema, L. (2019). Childhood obesity in urban Ghana: evidence from a crosssectional survey of in-school children aged 5-16years. BMC Public Health 19, 1-12. 1561 https://doi.org/10.1186/s12889-019-7898-3.

[24] Ghana Statistical Service (2014a). Ghana demographic and health survey. Accra: GSS and ICF Macro.

[25] Ghana Statistical Service (2014b). Population and housing census of Ghana. Analysis of Districts Data and Implications for Planning, Accra: Ghana Statistical Service.

[26] Gibson, R. S. (2005). Principles of nutritional assessment. Oxford, UK: Oxford University Press.

[27] Goldfield, G. S., Moore, C., Henderson, K., Buchholz, A., Obeid, N., \& Flament, M. F. (2010). Body dissatisfaction, dietary restraint, depression, and weight status in adolescents. J Sch Health, 80, 186-92.

[28] Gortmaker, S. L., Swinburn, B., Levy, D., Carter, R., Mabry, P. L., Finegood, D., Huang, T., Marsh, T., \& Moodie, M. (2011). Changing the future of obesity: Science, policy and action. Lancet. 27, 838-847. doi: 10.1016/S01406736(11)60815-5.

[29] Haslam, D. W., \& James, W. P. (2005). Obesity. National Library of Medicine, 366(9492), 1197-209. doi: 10.1016/S0140-6736(05)67483-1. PMID: 16198769.

[30] Himes, J. H. \$., \& Dietz, W. H. (1994). Guidelines for overweight in adolescent preventive services Recommendations from an Expert Committee. The Expert Committee on Clinical Guidelines for Overweight in Adolescent Preventive Services. Am J Clin Nutr. 59: 307-16.

[31] Institute of Medicine (US) Subcommittee on Military Weight Management. Weight Management: State of the Science and Opportunities for Military Programs. Washington (DC): National Academies Press (US); 2004. 3, Factors That Influence Body Weight. Available from: https://www.ncbi.nlm.nih.gov/books/NBK221834/

[32] Israel, M., \& Hay, I. (2006). Research Ethics for Social Scientists, London: Sage Publications Ltd.

[33] Krejcie, R. V., \& Morgan, D. W. (1970). Determining sample size for research activities. Educational and Psychological Measurement, 30, 607-610.

[34] Krushnapriya, S., Bishnupriya, S., \& Ajeet, S. B. (2015). Childhood obesity: causes and consequences. J Family Med Prim Care, 4(2), 187-192.

[35] McLaren, L. (2007). Socioeconomic status and obesity, Epidemiol Rev, 29:29-48 DOI: 10.1093/epirev/mxm001

[36] Mohammed, H., \& Vuvor, F. (2012). Prevalence of childhood overweight/obesity in basic schools in Accra. Ghana Med Journal, 46(3):124-7.

[37] Morita, Y., Iwamoto, I., Mizuma, W., Kuwahata, T., Matsuo, T., Yoshinaga, M., \& Douchi, T. (2006). Precedence of the shift of body-fat distribution over the change in body composition after menopause. Journal of Obstetrics and Gynecology, 32, 513-516.

[38] Muhihi, A.J., Mpembeni, R.N.M Njelekela, M.A., Anaeli, A., Sulende, O.C., Lujani, K.B., Maghembe, M., \& Ngarash, D. (2013). Prevalence and determinants of obesity among primary school children in Dar es Salaam, Tanzania. Archives of Public Health; 71:26 http; /www/archives of public health.com/content71/1/26.

[39] Ng, M., Fleming, T., Robinson, M., Thomson, B., Graetz, N., Margono, C., \& Abera, S. F. (2014). Global, regional, and national prevalence of overweight and obesity in children and adults during 1980-2013: A systematic analysis for the global burden of disease study 2013. The lancet, 384(9945), 766-781.

[40] Nicklas, T. A., Baranowski, T., Baranowski, J. C., Cullen K., Rittenberry, L., \& Olvera, N. (2001). Family and childcare provider influences on preschool children's fruit, juice, and vegetable consumption. Nutrition Reviews, 59(7), 224-235.

[41] Niehoff, V. (2009). Childhood obesity: A call to action. Bariatric Nursing and Surgical Patient. Care, 4:17-23.

[42] Pangani, I, N., Kiplamai, F, K., Kamau, J, W. \& Onywera, V. O. (2016). Prevalence of overweight and obesity among primary school children aged 8-13 years in Dar es Salaam City, Tanzania, Advances in Preventive Medicine, https://doi.org/10.1155/2016/1345017

[43] Popkin, B.M. (2011). Contemporary nutritional transition: determinants of diet and its impact on body composition; Proc Nutr Soc, 70(1):82-91.

[44] Sahoo, K., Sahoo, B., \& Bhadoria, S. B. (2015). Childhood obesity: Causes and consequences; J Family Med Prim Care. 4(2), 187-192.

[45] Schwimmer, J. B., Burwinkle, T. M., \& Varni, J. W. (2003). Health-related quality of life of severely obese children and adolescents. JAMA. 289, 1813-9.

International Journal of Research -GRANTHAALAYAH 
[46] Smith, J. D., Fu, E., \& Kobayashi, M. (2020) ... Prevention and management of childhood obesity and its psychological and health comorbidities. Annu Rev Clin Psychol, doi: 10.1146/annurev-clinpsy-100219060201

[47] Story, M, Neumark-Stainzer. D., \& French, S. (2002). Individual and environmental influences on adolescent eating behaviours. J Am Diet Assoc. 2002 102: S40-51.

[48] Tanofsky-Kraff, M., Yanovski, S. Z., Wilfley, D. E., Marmarosh, C., Morgan, C. M., Yanovski, J. A. (2004). Eatingdisordered behaviours, body fat, and psychopathology in overweight and normal-weight children. J Consult Clin Psychol, 72, 53-61.

[49] Trasande, L., \& Chatterjee, S. (2012). The impact of obesity on health service utilization and costs in childhood. Obesity, 17(9), 1749-1754.

[50] Truswell, A. S. (2003). ABC of nutrition (4th ed. Vol. 92), London: BMJ Books.

[51] Tuoyire, D. A., McNair, S., Debrah S, A., \& Duda, R.B. (2018). Perception of risk for hypertension and overweight/obesity in Cape Coast, Ghana. Ghana Med J. 52(3): 140-146. doi: 10.4314/gmj. v52i3.6

[52] Whyte, N. S., Amissah, A. A., \& Mensah, J. (2020). Strategies for managing childhood obesity in primary schools in the Cape Coast Metropolis of Ghana. Asian Journal of Contemporary Education. 4(1) 41- 56.

[53] World Health Organization (2007). Reference Curves ebook.ecog-obesity.eu/chapter-growth-charts-bodycomposition/world-health-organization-referencecurves. 